\title{
Teaching Moral Philosophy in the Behavioral Sciences: An Efficacy Study
}

\author{
Russell Fulmer ${ }^{1}$ \\ ${ }^{1}$ The Family Institute at Northwestern University, Counseling@Northwestern, Evanston, Illinois, United States \\ Correspondence: Russell Fulmer, Northwestern University, Evanston, Illinois, United States. E-mail: \\ Russell.Fulmer@northwestern.edu
}

Received: May 25, 2018 Accepted: June 13, 2018 Online Published: June 15, 2018

doi:10.5539/jedp.v8n2p62 URL: http://doi.org/10.5539/jedp.v8n2p62

\begin{abstract}
Normative ethics is the philosophical basis for the American Psychological Association's (2010) Ethical Principles of Psychologists and Code of Conduct, the applied ethics by which the psychology profession is governed. Concerned with the theories that help to determine right and wrong, normative ethics is an indispensable yet ostensibly inaccessible realm of study for clinical psychologists. This article presents a comprehensible exercise that professors and supervisors versed in normative ethics can administer to students and clinicians in training to help them clarify and articulate their beliefs. Results are presented that support the efficacy of the exercise in terms of increased normative awareness, heightened self-knowledge, and broadened worldviews. Implications for the utility of the exercise in the clinical psychology and health fields at large are also discussed.
\end{abstract}

Keywords: normative, ethics, awareness, worldview, exercise, right and wrong

\section{Introduction}

Every clinical psychologist has in his or her personal worldview conceptions of what is the right action and what is the wrong action. Professionally and personally, the question, "What is the right thing to do?" is asked repeatedly throughout the course of a lifespan. This question, often imperceptibly explored and implicitly answered, results in explicit action. A clinician's answers to this frequent question, therefore, have numerous clinical ramifications, from confidentiality dilemmas to the theoretical approaches driving his or her practice.

The professional foundation for competent clinicians is ethics (Freeman, Engels, \& Altekruse, 2004). Without ethics, no amount of brilliance, pedigree, or technique can salvage a practice, let alone allow a career to prosper. An ethical clinician wears many hats: trusted keeper of confidential information, believer in client autonomy, and provider of empathy (Remley \& Herlihy, 2013). But the true heart of ethics is morality, which implies notions of what is right, what is wrong, how to know the difference, and where this philosophical rationale originates (Welfel, 2016). It has been argued that there are no moral facts, or no objective truth able to motivate our decision-making (Mackie, 1977). While ethical codes exist in nearly all professions to help guide and even mandate action, each practicing clinician has broad latitude for clinical judgment in his or her day-to-day work (Ægisdóttir et al., 2006). It is during these times that a clinician must often make a judgment call. With heightened awareness of norms, such a judgment call can be a more educated one, informed by reason rather than caprice or ignorance.

Normative awareness is important because it is education of the heart and belief system, and evidence supports that beliefs guide or direct behavior (McKay, Davis, \& Fanning, 2011). While all clinicians exercise judgment and make decisions based on beliefs of right and wrong, few consider the specific rationale behind these decisions (Welfel, 2016). Therefore, it logically follows that a more reasoned understanding of the how, why, and what of right and wrong leads to more reasoned decision-making. Reason is the driving force behind science-including psychology, the behavioral science in which clinicians receive their training. Hence, there is a robust connection between the more overt sciences and the relatively abstract field of ethics (Pigliucci, 2003).

\subsection{Theoretical Rationale}

The efficacy of teaching ethics is a questionable proposition (Ruiz \& Warchal, 2014). Two questions necessitate the answer to the question of effectiveness. The first question is, what are the course objectives? There is evidence that some objectives can be accomplished, such as the improvements of students' self-knowledge, ethical sensitivity, moral cognition, and alerting students to the multitude of pathways available to arrive and right and 
wrong, hence addressing an ethical dilemma (Brinkmann \& Sims, 2001; Corey, Corey, \& Callanan, 2005). As self-knowledge is linked to mindfulness, this connection has particular relevancy to clinical psychology (Carlson, 2013). The second question is, do normative and meta-ethics enhance learning in an applied ethics course? The practice of teaching moral philosophies in applied medical ethics has long been accepted, although some suggest the practice should be reduced (Lawlor, 2007). Still, the majority opinion is there is room for moral theories in applied ethics courses (Saunders, 2010; Benatar, 2009). There is skepticism that professors can teach ethics in a way that translates to ethical behavior (Dudani, 2014; Bowden \& Smythe, 2008). Nonetheless, improvements in knowledge and comprehension of moral theories, knowledge about the self, and potential benefits for mindfulness practice, suggests an educational benefit for students.

\subsection{Aim and Focus}

This article presents an exercise designed to increase normative awareness - an under-recognized realm of ethics with the potential to yield tremendous power in a psychologist's professional life. Even small increases in normative awareness may lead to clinical differences in how affect, cognitions, and behaviors of clients are evaluated and subsequently treated (Magelssen, Pedersen, \& Førde, 2016). The four primary ways by which clinical psychologists benefit from practice in normative-awareness are: 1) confronting one's own existential challenges that undermine strides toward living a more meaningful, moral life, 2) bringing into consciousness the knowledge and comprehension of where one's core beliefs originate, 3) clarifying one's moral stance, sense of professional purpose, and overall self-identity, 4) fostering self-confidence by way of self-awareness, self-acceptance, and the Aristotelian assertion of knowing thyself.

It was hypothesized that by administering this exercise to students and clinicians in training, their beliefs get explored and articulated early, increasing normative awareness and self-knowledge at a pivotal juncture of professional development. Quantitative and qualitative results support this hypothesis with evidence of heightened normative awareness and broadened worldviews. From greater empathy to clearer case conceptualization, normative awareness is an invaluable clinical tool for mental health professionals.

\section{Method}

\subsection{Participants}

This research serves to shed light on the practice of broadening a fledgling clinician's personal worldview, rather than changing it. Exercise participants $(N=43)$ were three consecutive years of graduate level students enrolled in a semester-long Introduction to Counseling course as they all sought degrees in Clinical Counseling. First semester, $n=15$ (13 females, 2 males); second semester, $n=15$ (14 females, 1 male); and third semester, $n=13$ (12 females, 1 males).

\subsection{Materials and Procedures}

The exercise was introduced to participants by the course professor as consisting of the following four steps: (a) writing a reflection paper, (b) learning about normative-ethics theories, (c) participating in a small group discussion, and (d) writing a revised reflection paper. Prior to administering the exercise, a pre-test with the following three Likert-scaled questions was given: 1) I understand the normative ethical underpinnings of applied psychological ethics codes, 2) I can speak insightfully about one or more normative ethical theories, and 3) I understand the connection between normative ethics and greater self-knowledge. The Likert scale consisted of five numbers with one labeled "very little" and five labeled "very much."

\subsection{Step 1: Reflection Paper}

The normative awareness exercise began with a short reflection paper that asked participants to ponder and write about the question, "How do you determine right and wrong?" providing the following prompts as guidance:

- When confronted with an ethical dilemma, what do you use to determine which course of action you will take?

- Are you more guided by principles or outcomes?

- Do you use more objective data or subjective values when determining right and wrong? What is an example?

- Do you believe that morality is determined by the impact your actions have on others, from doing what makes sense, or from a supernatural source?

- Do you believe that morals are universal to everybody or relative to each person? 


\subsection{Step 2: Normative Ethics Education}

Next, the professor lectured over the various theories that address normative ethics defining, in essence, the philosophical approaches one can use to determine, "What should I do?" The emphasis of the lecture was on the core meaning of each theory (e.g. deontology as a means-based ethic that suggests that the right course of action resides in abiding by one's duty to a law, an authority, or a reason). The professor offered clinical examples throughout and students were encouraged to come up with their own examples to volunteer during the lecture. The Normative Ethics terminology sheet (see Appendix A) was offered to students as a supplement and reference to the lecture.

\subsection{Step 3: Small Group Discussion}

Students were asked to team up into smaller units to discuss what insights they gained from the lecture on normative theories, being granted liberal permission from the professor to keep certain feelings and beliefs private. This opportunity also served to clarify any misunderstandings. The professor, circulating and readily available, answered questions or provided additional input as initiated.

\subsection{Step 4: Revised Reflection Paper}

The final step in the normative awareness exercise was to write a second reflection paper. Students were asked again to address how they determine right and wrong, this time with increased knowledge following education of the theories of normative ethics and a focused discussion with peers on the topic.

A post-test consisting of the same three Likert-scaled questions was administered $(N=41)$ upon completion of the normative awareness exercise. Qualitative data was also collected by way of a comments section at the end inviting the following: Please leave any feedback about the normative awareness exercise.

\section{Results}

The pre-test mean $(N=43)$ was 1.25 with a standard deviation of .46 . The post-test mean $(N=41)$ was 4.25 with a standard deviation of .70 (See Table 1). A paired t-test run on the sample yielded statistically significant results (p $=<.0001$ ) (See Table 2). From the qualitative data collected, the following five examples of student feedback are illustrative of the exercise and its efficacy in increasing normative awareness: 1) The activity taught me a lot about ethics at a deeper level than the textbook gets into, 2) The activity gave a name to what I believe and in doing so helped me clarify my own ethical code, 3) Loved the ethics exercise! I am an intuitionist and I didn't know it! 4) I now look at the [professional] ethics code differently. Applied ethics are opinion of the majority if not based on a normative theory. How many counselors know this? I doubt many. Those of us who completed the exercise do, and 5) Can't say I totally understand deontology and consequentialism but I know more now than before. Before I couldn't tell you anything about normative ethics.

Table 1. Intro to Counseling Students' Normative Awareness Pre- and Post-Exercise

\begin{tabular}{lllll}
\hline Group & N & Mean & SD & SEM \\
\hline Pre & 43 & 1.25 & 0.46 & 0.16 \\
Post & 41 & 4.25 & 0.70 & 0.25 \\
\hline
\end{tabular}

Table 2. Paired Sample T-Test

\begin{tabular}{|c|c|c|c|c|c|c|c|}
\hline & \multirow[t]{2}{*}{ Mean } & \multicolumn{2}{|c|}{$\begin{array}{l}95 \% \text { Confidence Interval of the } \\
\text { Difference }\end{array}$} & \multirow[t]{2}{*}{$\mathrm{t}$} & \multirow[t]{2}{*}{$\mathrm{df}$} & \multirow{2}{*}{$\begin{array}{l}\text { Std. error of } \\
\text { difference }\end{array}$} & \multirow[t]{2}{*}{ Sig. (2-tailed) } \\
\hline & & Lower & Upper & & & & \\
\hline $\begin{array}{l}\text { Pre minus } \\
\text { post }\end{array}$ & -3.00 & -3.45 & -2.55 & 15.875 & 7 & 0.189 & $<.0001$ \\
\hline
\end{tabular}

\section{Discussion}

As expected, students completing an explicit practice in normative ethics reported a measurable increase in the comprehension and articulation of the beliefs they rely upon to answer the question of what is the morally correct course of action. Designed solely to heighten normative self-awareness, this activity does not aim to tell a student what to believe or to intrude upon sensitively held beliefs. In fact, it is more likely to introduce new vantage points 
than to revolutionize a person's existing moral framework. Ultimately, each clinician walks his or her own moral pathway, so this exercise could be compared to a road map replete with myriad routes to travel. Supervisors and professors, therefore, act as both mentors and navigators, granting students and clinicians in training the opportunity to choose their moral paths accordingly.

While the exercise is recommended to be administered in its entirely, benefits can be garnered from portions of it as well. For example, all clinical mental health students enrolled in an ethics were required as part of their degree training to complete the normative awareness reflection paper. M.S., a first year student in mental health counseling, provided feedback on the exercise: "I now have a better understanding of why I make the decisions I do. Before the exercise I never sat down and thought about my thought processes, which are extremely important. Working through the exercise helped me analyze a part of myself I never had thought much about before. Now I know myself better." This student's summation underscores a greater awareness of self, something from which students in other fields, including medicine, could also benefit (Sugarman \& Sulmasy, 2001).

Medical students often enter medical school with backgrounds as EMTs or other experience in health care. Consequently, they are familiar with ethical dilemmas and matters of ethics wherein value judgments must be made. As part of a medical curriculum, students were required to take a course in ethics in which this activity was conducted. Many students reported the activity as an insightful one. "Eye-opening and challenging, it made me think about things I never had done before," said one. Another reported, "This activity showed me that my patients may use a number of ways to decide what the best course of treatment is for them. I will use this to understand their point of view and establish a stronger relationship with them."

Experienced mental health clinicians completing the exercise reflected on their normative awareness as well. In the view of one, "I got into counseling for self-growth, and self-growth includes awareness. Exercises like this enable me to see the legitimate perspectives of others." It is not uncommon for clinicians to be initially reserved about disclosing their moral foundations. They, like most other people, are accustomed to perceiving morality as sacred ground that ought not be crossed. This exercise explores notions of right and wrong in a non-threatening, education-driven way. The purpose is not to convince or alter a person's deeply held beliefs, but rather to simply raise awareness and increase knowledge.

Regardless of the professional position of the participant, the administrator should insert his or her own clinical examples throughout the exercise to elucidate the educational components and to foster an open dialogue with the student or clinician. This serves the dual purpose of showing the exercise's practical relevance and preventing personal defensiveness. For example, one clinician was seeing a client who reported feeling depressed after losing his grandmother. Acting as a surrogate, the client was forced to decide whether or not to continue life support when his grandmother's condition rendered her incapacitated. Long after her passing, he struggled with whether the decision he made was the right one. From the normative-awareness exercise, the clinician reported an increased capacity to empathize with the client because the clinician better understood the two normative systems between which the client felt trapped. The client was not aware of the two conflicting systems causing his grief, and the clinician discussed the myriad ways available to determine right from wrong. Although this knowledge alone did not solve the client's problem, the clinician credits it as a transformative moment in session that allowed the therapy to progress.

Ideally, measuring progress in the domain of normative awareness involves revisiting the normative exercise periodically with the assistance of a competent supervisor. Following completion of the exercise, participants (whether licensed clinicians or student interns), will likely maintain or advance in their professional roles and could benefit from following up with a supervisor who inquires about their current thoughts on normative awareness, processes any lingering questions or concerns, and helps the clinician reconcile and integrate any adopted norms into his or her belief system.

Even participants without a trained supervisor nearby can take steps to measure their own progress following completion of the exercise. Because normative thought processes are personal and held close to the heart, they are sometimes hard to articulate, especially prior to completing the exercise. Clinicians able to clearly articulate their belief systems, who can fluently express the origins of their notions of right and wrong, have reached an advanced phase of normative awareness. Likewise, clinicians can monitor their progress by way of written expression. Journaling is useful in that it allows the clinician to continually process what is likely to be an ever-evolving worldview. Normative awareness is a process - one with many levels of progression. Each stage can be observed and noted for signs of progress through clear expression of language.

Though the implications for the application of this normative awareness exercise in the clinical health fields are myriad and far-reaching, precautions should be taken. Advised against participating include those convalescing 
from a trauma, actively bereaving a loss, or undergoing significant amounts of change; emotional and physical states can be particularly fragile and vulnerable at these times (Magyari, 2016). Any clinicians experiencing these life circumstances ought to proceed with caution and under the competent supervision of a professor or practicing clinician.

By its nature, this exercise in normative awareness challenges students and clinicians to clarify and justify their beliefs. Although not purposefully provocative, the exercise is capable of bringing about resistance and defensiveness. It should be administered by a supervisor skilled in processing any feelings of discomfort that arise and by one committed to reassuring students and clinicians that challenging beliefs is not tantamount to questioning a belief's worth or accuracy. The supervisor should aspire to educate, comfort, and collaborate with the student or clinician as he or she clarifies personal and professional beliefs about right and wrong. The four steps of the activity, from the first reflection paper to the last, are designed to provide sufficient time and space for the student or clinician to glean, process, and integrate profound information into their valuable worldview.

Quite often, a great deal of what a person does or does not do can be traced back to normative beliefs. Most people strive to do the morally right thing; yet ironically, most normative theories remain unknown to the majority of people, even within the field of clinical psychology. This activity aspires to raise normative awareness, allowing clinicians to not only understand themselves more fully, but to also see their clients in a newer, more compassionate, and more vibrant light.

\section{References}

American Psychological Association. (2010). Ethical Principles of Psychologists and Code of Conduct. Washington, DC: Author.

Ægisdóttir, S., White, M. J., Spengler, P. M., Maugherman, A. S., Anderson, L. A., Cook, R. S., ... Rush, J. D. (2006). The meta-analysis of clinical judgment project: Fifty-six years of accumulated research on clinical versus statistical prediction. The Counseling Psychologist, 34(3), 341-382. https://doi.org/10.1177/0011000005285875

Benatar, D. (2009). Teaching moral theories is an option: reply to Rob Lawlor. Journal of medical ethics, 35(6), 395-396. https://doi.org/10.1136/jme.2008.028761

Brinkmann, J., \& Sims, R. (2001). Stakeholder-sensitive business ethics teaching. Teaching Business Ethics, 5, 191-193. https://doi.org/10.1023/A:1011461418842

Carlson, E. N. (2013). Overcoming the barriers to self-knowledge: Mindfulness as a path to seeing yourself as you really are. Perspectives on Psychological Science, 8(2), 173-186. https://doi.org/10.1177/1745691612462584

Corey, G., Corey, M. S., \& Callanan, P. (2005) An approach to teaching ethics courses in human services and counselling. Counseling and Values, 49(3), 193-207. https://doi.org/10.1002/j.2161-007X.2005.tb01022.x

Dudani, S. (2014). Stanford panel debates: Does teaching ethics do any good? Stanford Report. Retrieved from https://news.stanford.edu/news/2014/may/ethics-in-society-051314.html

Freeman, S. J., Engels, D. W. \& Altekruse, M. K. (2004). Foundations for ethical standards and codes: The role of moral philosophy and theory in ethics. Counseling and Values, 48, 163-173. https://doi.org/10.1002/j.2161-007X.2004.tb00243.x

Huemer, M. (2008). Ethical intuitionism (1st ed.). New York, NY: Palgrave Macmillan.

Kagan, S. (1997). Normative ethics. Boulder, CO: Westview Press.

Lawlor, R. (2007). Moral theories in teaching applied ethics. Journal of Medical Ethics, 33(6), 370-372. https://doi.org/10.1136/jme.2006.018044

Mackie, J. L. (1977). Ethics. Inventing Right and Wrong, London: Pelican Books.

Magelssen, M., Pedersen, R., \& Førde, R. (2016). Four roles of ethical theory in clinical ethics consultation. The American Journal of Bioethics, 16(9), 26-33. https://doi.org/10.1080/15265161.2016.1196254

Magyari T. (2016). Teaching individuals with traumatic stress. In D. McCown, D. Reibel, \& M. Micozzi (Eds.), Resources for Teaching Mindfulness (pp. 339-358). Switzerland: Springer, Cham. https://doi.org/10.1007/978-3-319-30100-6_18

McKay, M., Davis, M., \& Fanning, P. (2011). Thoughts and feelings: Taking control of your moods and your life (4th ed.). Oakland, CA: New Harbinger Publications. 
Pigliucci, M. (2003). On the relationship between science and ethics. Journal of Religion and Science, 38(4), 871-894. https://doi.org/10.1111/j.1467-9744.2003.00544.x

Remley, T. P., \& Herlihy, B. (2013). Ethical, legal, and professional issues in counseling (4th ed.). Boston, MA: Pearson.

Ruiz, A. \& Warchal, J. (2014). Ethics as an undergraduate psychology outcome: When, where, and how to teach it. Psychology of Learning and Teaching, 13(2). 120-128. https://doi.org/10.2304/plat.2014.13.2.120

Saunders, B. (2010). How to teach moral theories in applied ethics. Journal of medical ethics, 36(10), 635-638. https://doi.org/10.1136/jme.2009.032052

Sugarman, J. \& Sulmasy, D. P. (Eds.). (2001). Methods in medical ethics. Washington, DC: Georgetown University Press.

Welfel, E. R. (2016). Ethics in counseling and psychotherapy (6th ed.). Boston, MA: Cengage Learning.

\section{Appendix A}

\section{Normative Ethics Terminology}

The American Pscyhological Association's Ethical Principles of Psychologists and Code of Conduct (APA, 2010) is an example of applied ethics, informed by the very philosophical theories used to determine what is right and what is wrong. Normative Ethics, like applied ethics, is a branch of philosophy. Below are some relevant terms to help clarify and differentiate the different theories and branches of ethics (Huemer, 2008; Kagan, 1997). The explanations represent philosophical fields used by human service professionals to determine right and wrong, albeit usually unwittingly. Simple definitions for what can be complex fields of study, they can be used by clinicians to refine their own codes of right and wrong and to better understand their clients' perspectives.

\section{Normative Ethics}

Ethical theories that help determine what one should morally decide based on different perspectives of what is the core feature of what is right and what is wrong.

Theory 1: Deontological. A duty-based ethic that says the moral right is staying obedient to a law, authority, or reason. Deontology suggests that the means trumps the ends.

Theory 2: Consequentialist. An outcome-based ethic that says the moral right is dependent upon positive results either for a group of people or the self. This is a results-focused theory that suggests that the ends trump the means.

Theory 3: Virtue. A character-based ethic that says the locus of right and wrong is based on disposition and character traits, rather than doing. Virtue ethics is concerned with the inherent person more than an analysis of the person's deeds.

Theory 4: Ethic of caring. An ethic stressing the subjective value system in determining right and wrong, a caring-focused ethic points out the interdependent nature of humans and suggests that relationships should be a deciding factor in choosing right from wrong.

Theory 5: Ethical intuitionism. Both a meta-ethical and normative theory, the idea is that right and wrong is self-evident; however, intuitionists suggest that intuitions are subject to skew by prejudice, misinformation, and any notions that bias the mind.

\section{Descriptive Ethics}

Comparative ethics that study what people believe. Descriptive ethics state what is believed, not what should be believed.

\section{Meta Ethics}

Studies ethics itself - the nature of values and evaluative statements (Are there objective values? Can we justify our beliefs?).

\section{Copyrights}

Copyright for this article is retained by the author(s), with first publication rights granted to the journal.

This is an open-access article distributed under the terms and conditions of the Creative Commons Attribution license (http://creativecommons.org/licenses/by/4.0/). 